DOI https://doi.org/10.18551/rjoas.2017-10.13

\title{
POLITICAL SUBJECTIVITY PHENOMENON OF STUDENT-AGE YOUTH
}

\author{
Kulikov S.P.*, Candidate of Sociological Sciences \\ Moscow Aviation Institute (National Research University), Moscow, Russia \\ Shchitov K.V., Chairman \\ Moscow City Duma's Commission for Physical Culture, Sports and Youth Policy, \\ Moscow, Russia \\ *E-mail: ncsrm@mail.ru
}

\begin{abstract}
The article addresses the phenomenon of the political subjectivity of student-age youth and the impact on student-age youth as a social group through the educational system of higher vocational training institutions. It is concluded that, without the participation in young student associations, it is impossible to shape a good professional, much less an innovative scientist, from a simple student.
\end{abstract}

\section{KEY WORDS}

Education, student days, political culture, factor, youth, discourse.

Today student-age youth are the most important social and political unit. This particular status of youth in the arena of political discourse is linked to a number of factors. These include, first and foremost, the possibility of influencing on student-age youth as a social group through the educational system of higher vocational education. Student-age youth are also a positive environment for the emergence, development and implementation of various innovative ideas. It is today's students that will become the foundation of the future of our society and determine in many ways what it will be. Although the intellectuals' environment hasn't been numerous in all historical eras, it has always been an elitist and decisive factor in the progress and prosperity of the nation as a whole. In addition, it is important to note that, in terms of modern psychology, the final stages of human personality shaping is chiefly associated with the student age, a period that is favourable to the development of values, since major stereotypes have not yet been formed or are fairly flexible. Moreover, it is also important that the student environment seek to participate actively in the political life of the community by seeking to organize social and political processes in accordance with their own perceptions and values. These factors make it possible to speak of the special nature of the representation of student youth in the social and political government system.

It is important to note that youth and the political system of society are not functioning in isolation, and in the process of political socialization, young people do not simply absorb the norms, somehow converting them into personal values, but enrich, alter, transform them, returning them to the society in an altered, more appropriate modern state, thus affecting society and the political situation. Society shapes a citizen in the process of political socialization, solving, first of all, educational tasks, but a properly nurtured citizen, then creates a new society that combines in its idea the reasonable tradition as well as the necessary innovation. What the future society will be depends entirely on how the work with young people, especially students, is organized today.

In our country, research on various aspects of youth issues has been conducted for a considerable period of time. The heightened interest of political scientists and sociologists in youth and youth policy is due, first of all, to the special nature of youth representation in the political arena, which is defined here as a phenomenon of political subjectivity of student-age youth. Let us consider the origin of these views.

The works of Russian scientists on the issues of youth policy are similar in concept and direction to those of Western European and American scientists. In general, political scientists share the view that young people are a reflection of the future development of society. However, in our country, the scientific consideration of youth issues has long been under ideological oppression, which has not contributed to the full reflection of the real social concerns of the subject. 
The first significant studies of youth political subjectivity began in the years of 1900-10. Three main areas of focus can be identified in the works of this period. First, young people are viewed as carriers of youth-age characteristics. It is not the young people themselves, but a period of "youth", i.e., the time-stage that the individual dwells in. This concept was discussed in the works of L.S. Vygotsky, A.N. Leontev, G. Stanley Hall, C. Bühler. The second area of research is youth as a sociocultural group with its own individual and exclusive properties ( $E$. Spranger, R. Benedict, B. Malinovsky, M. Mead etc.) The third approach considered youth from the point of view of generation alternation and succession (sociologists of Marxist school such as K. Mannheim, M. Scheler, G.B. Lukács). Further research on youth reflects the social and political processes associated with the global revolutionary changes that led to the establishment of the socialist camp. The scientific works here could also be divided into three major groups. This classification was based on a review of a particular type of youth. In the first group, researchers devoted their work to the issues of the so-called working youth. This category was virtually forgotten in Tsarist Russia, and in the 1920s it became crucial. "A Teen Worker" (Aryamov I.A., 1928), "Work and Everyday Life of Teenagers" (Zaitsev V.A., 1926), "Working Youth's Life" (Kogan B.B., Lebedinsky M.S., 1929) were released. Research for this category was aimed at understanding the specific needs of young people, the dependency of social inclusion, the nature and working conditions. A second group of researchers considered early youth movements. Based on the sad life lessons of a bygone era, scientists attempted to offer the state effective mechanisms for the creation of youth communities whose activity would be aimed at the good of the state rather than at harming it. For example, "Revolution and Youth" by A.B. Zalkind [1] is devoted to this issue. The third social category, which had attracted researchers, which was the most organized was young people who are studying. The study of young people who are studying at that time took place in the context of the establishment of a universal educational system that was to be used in the Soviet educational institutions. Among the most important and relevant scientific concepts, we should mention the concept of child and juvenile collective upbringing and re-education by the Soviet teacher, A.S. Makarenko. The concept called for the creation of youth groups of the united by ideologised tasks that would ensure that young people were kept from any kind of anti-state and anti-social sentiment and that they would educate them in a spirit of respect and love for their nation. The later idea of the communist human upbringing, developed by V.A. Sukhomlinsky, is also important and considers the needs of secondary and higher technical education. In his educational concept, Sukhomlinsky relied on the strength of human, especially ideological, social and political disciplines and the educational influence of the student body as an organized group. In the early 1990s, these works were labeled overly politicized, aimed at the total subordination of the ideology of the regime. However, it is noteworthy that, until now an consistent scientific and practical concept of educating young people hasn't been offered.

At present, research on youth issues has not only preserved its relevance, but has also become essential for the socio-economic and political development of the country. Since the collapse of the USSR and the establishment of the democratic regime in the country, young people have become one of the most numerous organized social groups in the state. All major processes in the country depend on its socio-economic behavior and, in particular, its electoral activity. The direction of research on youth has changed, and several factors have been involved. First, with the adoption in 1991 of the Law «On General Principles of State Youth Policy in the USSR», which enshrined the interpretation of state youth policy as the activities of the state "with a view to creating socio-economic, institutional and legal conditions and guarantees for the social development and advancement of young citizens, their fullest realization in the interest of society as a whole" [2]. Secondly, with a change in understanding of the youth's problems. In the past, it was commonly believed that social and, especially, political problems could be confined to some particular young people, or, at least, to small groups of asocials, but in the early 1990-s, it was more daring to speak of social and political problems of Russian youth in general. Much of this change in approach was due to the rather complex socio-economic situation that deprived young people of active support on the part the State and presented them with the task of survival. However, this statement does not speak of the inhumane nature of the Russian society's youth policy of this period. All civil society was under difficult circumstances. And while the economic problems of citizens were key, the large-scale ideological crisis was as much a concern to political scientists as the former one: "To survive and to preserve itself on the planet, mankind will have to reinvigorate 
the old and find new values, adopt a new paradigm of life, new thinking, new rules of coexistence and new morality" [3]. These words of I.M. Ilyinsky can be attributed precisely to the ideological crisis, which has greatly aggravated the political situation in the country, making it unstable, and attempts by the authorities to establish a dialogue with the people were not constructive. The core issue of the youth environment, which is sensitive to all societal cataclysms, has become nihilism, denial of authority, non-recognition of moral values and social as well as political apathy.

Considering social and political activity of the youth, attention needs to be given to the formation of a young person's political culture. Unfortunately, methodologists today have no consensus as to its formation, as well as to the relationship between political culture, beliefs and behavior. Of course, the role of the higher education institution is important in this work, which, first of all, is the force of the educational disciplines of the humanitarian profile to form a political culture. However, even a high level of political culture can be combined with an apathetic civic position. In addition to knowledge and perceptions, there must also be a proper level of political activism and activity, and here the leading role belongs to extracurricular educational work, which contributes to the implementation of the perceptions acquired to the personal directions of activity. The extracurricular educational work of a higher educational institution is a systematic approach whose basic core is youth organizations and associations. They ensure the political socialization of students by guiding youth activity into the necessary direction of the political system. However, their work will not be successful unless the proposed (by the authorities) initiatives are in conformity with the personal views and values acquired through the "classroom interaction" process which is the basis of the political culture. We believe that in order for youth policies to succeed, the young people must be guided by the following: Political consciousness, built on the ideals of humanism, democracy, tolerance and political activism, which seeks to change the reality towards the adoption of these principles. Only youth student inter-university associations can give the young person the first experience of successful political activity and make the student a real actor [in the sociological sense] in the political arena.

\section{REFERENCES}

1. Zalkind A.B. Revolution and youth. Moscow, 1924, p.35.

2. The USSR Law «On General Principles of State Youth Policy in the USSR» // Izvestiya. 1991, May 2. P. 2

3. Sheregi, Arefyev, 2003; Current drug problems in young people's environment, 2004.

4. Ovchinnikov V.V. Student's Self-government in Russia: sociological analysis: Thesis for the candidate of sociological sciences. Moscow, 2007.

5. Novikov S.V. The national economy is a large-scale organizational socio-economic system. "Vestnik of University". 2014. No.6. Pp. 125-132.

6. Sorokin A.E. Innovation and Technology management in the organization of scienceintensive production. "Innovatsii". 2016. No.10 (216). Pp. 132-136.

7. Novikov S.V. Framework for the management of state and municipal orders. Training manual for students / Moscow, 2012.

8. Volkov Y.G. Role of creative social practices in the development of united activities in Russian society. Int. Journal of Env. and Sc. Ed. 2016. 11. No.16. Pp. 9398-9409.

9. Kulikov S.P. The patriotic education of youth as the main focus of youth policy. Vestnik of Moscow State Regional University. Series: Pedagogy. 2015 No. 2. Pp. 140-145.

10. Yurkina L.V. The harmonious educational space of the technological higher educational institution is the key to building citizenship. Eur. Soc. Sc. J. 2013. No.3(31). Pp. 55-60.

11. Kulikov S.P. The patriotic education of youth as the main focus of youth policy. Vestnik of Moscow State Regional University. Series: Pedagogy. 2015 No.2. Pp. 140-145.

12. Zolotukhina E.B. Sales management of the chain retail establishments. International Journal of Applied Business and Economic Research. 2017. Vol. 15. Issue 11. pp. 19-27. 